\title{
Research on Public Participation in Recording Intangible Cultural Heritage in Rural Area
}

\author{
Yanling Guo ${ }^{1^{*}}$, Yonghui Wang ${ }^{2}$ \\ ${ }^{1}$ School of Management, Hebei University, Baoding City, Hebei Province,China \\ ${ }^{2}$ School of Management, Hebei University, Baoding City, Hebei Province, China
}

\begin{abstract}
Being an important part of cultural heritage, intangible cultural heritage (hereinafter referred to as "ICH") needs to be passed down from generation to generation. Seemed as the gene of national cultures, ICH is very important for the development and prosperity of human culture, for the development of social economy and civilization, and for the identity of individuals and ethnic groups. Since the publication of the Convention for the Safeguarding of the Intangible Cultural Heritage in 2003, ICH safeguarding activities have been fully implemented throughout the world. Recording ICH is a basic and important way to safeguard ICH, this way plays an important role and has been widely approved throughout China and other countries. It has been applied in many ICH item safeguarding, such as Nanjing Yunjin, Qinhuai Lantern Festival. As we all know, ICH resources are very rich in China. There are $39 \mathrm{ICH}$ items have been listed in " the Representative List of the Intangible Cultural Heritage of Humanity", 1,372 ICH items have been listed in "the Representative List of the Intangible Cultural Heritage in China". There are a large number of famous and not famous ICH items scattered in urban areas. To record so many ICH resources, it is not enough to rely on the power of the government. As the creator and inheritor of ICH, the public should play an important role in the safeguarding activities. Attracting the public to participate is a prerequisite of ICH safeguarding. Through questionnaires, interviews and other research methods, this paper introduces the public's awareness and attitude about recording ICH, and their ability and willingness to participate in ICH safeguarding activities. Based on the current status, It analyzes the advantages of public participation in the protection of $\mathrm{ICH}$, and the disadvantages, opportunities and threats are also analyzed. Based on the international principle of "government-led, public participation", this paper proposes to construct a "folk-government" model to optimize the quality of recording $\mathrm{ICH}$. To ensure the quality of public participation, it further points out that some measures should be taken, such as strengthen the government leadership to provide necessary support, identifying their advantages and responsibilities of different participants to joint, expanding the participation content and diversifying the participation method. These measures are all aimed at promotion the safeguarding and inheriting the ICH.
\end{abstract}

* Corresponding author: yanlingguo02@163.com 


\section{Introduction}

Since the publication of the Convention for the Safeguarding of the Intangible Cultural Heritage in 2003, the safeguarding of intangible cultural heritage (hereinafter referred to as "ICH") has been fully implemented throughout the world. In China, the national ICH inheritor recording project has been launched in 2015, and the national ICH recording project has been launched in 2017. A large amount of records are created. ICH records include all kinds of documentation during the process of ICH safeguarding and inheritance, such as text, photographs, sound and video recordings. These records are products of ICH safeguarding and inheritance, and also are the basis for further safeguarding and inheritance. With the development of $\mathrm{ICH}$ recording project, a large number of $\mathrm{ICH}$ distributed in rural areas that never attracted the attention of national government departments can be effectively protected by records. The public, as the familiar and inheritor of ICH is bound to become the main force in the ICH recording project. Relative to government agencies, public refers to all individuals and organizations, including inheritors, non-governmental organizations, and ordinary persons who maybe participate or interested in ICH safeguarding.

Different members are different in values, knowledge structure, cultural literacy, and social responsibility. These factors determine their different performance in recording ICH. Generally, there are quality problems exited in records in terms of authenticity, integrity, systematicity, security, etc. Based on the status of public participation in the safeguarding of $\mathrm{ICH}$, this paper discusses strategies to optimize public participation in recording ICH

\section{Material and Methods}

Through questionnaires, interviews and other research methods, this paper introduces the public's awareness and attitude about recording $\mathrm{ICH}$, and their ability and willingness to participate in ICH safeguarding. Based on the current status, it analyzes the advantages of public participation, and the disadvantages, opportunities and threats are also analyzed.

\subsection{The realistic foundation of public participation in recording ICH}

\subsubsection{Wide participation in the safeguarding of $\mathrm{ICH}$}

With the public cultural consciousness and cultural self-confidence have been gradually improved, the public has become an important force in the safeguarding of ICH. They have participated in most safeguarding activities, from the application for the list of heritage, the identification of inheritors, the construction of training school, and the construction of the ecological and cultural area. The wide application of high technologies such as mobile internet and new media provides a more efficient platform for public participation in the safeguarding, inheritance, propaganda and innovation of ICH. For example, in "the First Intangible Cultural Heritage Innovation and Design Competition" launched on April 2018, it has attracted more than 20 teams including university students, Internet companies and cultural companies.

\subsubsection{Public participation in the safeguarding of $\mathrm{ICH}$ has received legal support}

Article 15 of the Convention for the Safeguarding of the Intangible Cultural Heritage declares that each State Party shall ensure the maximum participation of community groups and individuals, and permit their active participation in management when carrying out ICH 
safeguarding activities. "Government-led, Social-participate" is also the general principle of ICH safeguarding throughout the world.Articles 9 and 10 in the Law of the People's Republic of China on Intangible Cultural Heritage clearly declares that "China encourages and supports citizens, legal persons and other organizations to participate in the safeguarding of $\mathrm{ICH}$, and organizations or individuals that make significant contributions should be rewarded." At present, the government pay more attention on the ICH that have been listed in certain safeguarding lists, and the higher the level, the more attention it attracts (for example, listed in " the Representative List of the Intangible Cultural Heritage of Humanity", "the Representative List of the Intangible Cultural Heritage in China"). While scattered in rural areas or undeveloped areas, a lot of ICH are rapidly disappearing because of their low level or not be listed. Public power is playing the key role in safeguarding and inheriting these ICH.

\subsubsection{The public may be the important force in recording $\mathrm{ICH}$}

Recording is the basic way to safeguard ICH. Especially for ICH which are weak and frangible, recording means a kind of rescue. The public is the familiar, inheritor, and beneficiary of the $\mathrm{ICH}$, the public has an natural advantage in the recording of $\mathrm{ICH}$. In China, from the early stage, folk songs, folk stories and myths are recorded and arrangement in "the Book of Songs", to the ten books of Chinese folk literature and art in the 1980 s, to the recording project of ICH nowadays, all these have demonstrated the public power in recording $\mathrm{ICH}$.

\subsection{Practical obstacles for the public to participate in recording ICH}

\subsubsection{Weak participation consciousness}

The government and the public are the two main forces in ICH safeguarding. But the two forces are not balanced and coordinated from the perspectives of laws and regulations formulating, ICH survey, and inheritor identification. In the era of "application for the heritage ", ICH are graded by government. Some ICH have been paid enough attention by national governments and international organizations (such as UNESCO), while a large number of ICH are facing vanished with the deaths of inheritors due to low grade. In the process of recording $\mathrm{ICH}$, the public is not familiar with what should be recorded, how to recorded, and related technologies and standards during recording activities. Public participation is also limited to passively obey the government arrangement during the field survey, records collection, and oral recording. The lack of consciousness of participation leads to lack of initiative, which leads to problems existed in the quality of records, such as not complete, not authenticity, not dynamic, etc.

\subsubsection{Insufficient capacity for public participation}

The traditional long-standing ICH has been seen as the blood and gene of local people. It is an integral part of the local mass's life. However, because lack of necessary knowledge and skills, public participation capacity in recording $\mathrm{ICH}$ is often not enough.

Firstly, knowledge about records management is not enough. ICH inheritors and the mass have accumulated and preserved a large number of records during their ordinary lives and activities. However, how to organize these records (including scientific classification, system arrangement, etc.), how to control the storage conditions to extend their life requires a amount of special knowledge. During the author's survey, it is often found that some 
precious records are lost, mildewed, and the disc cannot be played. Secondly, with the wide application of a large number of technologies, digital devices (such as digital cameras, smart phones, computers, etc.) are needed to record ICH, this is difficult and not reachable for people who are old and live in rural area.

\subsubsection{Limited in content and participation ways}

Recording enables ICH to be "preserved and passed on". At present, public participation is not enough in the process of investigation, recording, preservation, inheritance and propaganda of ICH. Generally, most of the public participation is limited only in the records collection stage, and the public participation is rarely in other stages, such as records information organization, data mining, publishing, database construction and management, website construction and operation, etc. Most of these activities are considered too professional, which directly prevent the public from participating. As to the participation ways, ICH recording is mostly government-led, and most of products are preserved in library, museum, archives, intangible cultural heritage centers and other related institutions. Therefore, public participation in ICH recording is controlled by government. The Limited content and participation ways of public participation inevitably lead to the disappear of a large number of traditional cultures.

\subsection{Optimization Strategies for Public participation in Recording ICH}

\subsubsection{Adjust the relationship between government and the public in recording ICH}

You are free to use colour illustrations for the online version of the proceedings, but any print version will be printed in black and white unless special arrangements have been made with the conference organiser. Please check whether or not this is the case. If the print version will be black and white only, you should check your figure captions carefully and remove any reference to colour in the illustration and text. In addition, some colour figures will degrade or suffer loss of information when converted to black and white, and this should be considered when preparing them.

"Government-led, Social-participate" is one of the international general principles in the safeguarding of ICH. "Government led" refers that the government should provide corresponding support to mobilize, organize, manage the safeguarding of ICH through management regulation designing, organizational construction, and funds providing. But in fact, many people(including government departments) misunderstand the "governmentled", and interpret it as the government should control all the safeguarding activities. This misunderstanding lead the government to too excessive participation in ICH protection, which has also led to the gap (estrangement) between government departments and inheritance groups. Recording ICH means dynamically recording the past, present, and future of all kinds of ICH items through records and so that the following generations can know about the traditional culture through records. The ICH can exist for a long time in form of records even if some traditional culture will disappear in the history. The public is the basic power of creating, thriving, inheriting and innovation of $\mathrm{ICH}$, so we must adjust the relationship between the government and the public in the process of recording $\mathrm{ICH}$.

Firstly, public participation means public participation should not limited in the scope of donation, oral recording, while should participate in the whole process of recording ICH, including collection, storage, arrangement and utilization of records. For example, public should participate in records appraisal, identifying the records authenticity and retention period, records compilation, exhibition, description, website designing and so on. 
Secondly, public participation means comprehensive participation, fully participating into the recording activities, regulation designing, organization system and funds support. Public should be fully given the right to know, to supervision and decision-making. Taking the regulation designing as an example, generally, most regulations including management regulation, operational norms as well as standards and specifications are drawn up by the government or relevant departments, the public only implement these regulations and standards. Public comprehensive participation should also participate in the regulations construction through public hearing, discussion, inspection, supervision and so on. The public's will, demands and realistic conditions should be given full respect. Public comprehensive participation ensure the regulations are scientific , and also ensure they are carried out smoothly.

Thirdly, public participation means all the public members' participation. During recording $\mathrm{ICH}$, the public should include all the groups and individuals that have actual or potential influence on the safeguarding of ICH. Different individuals and groups with different cultural literacy and knowledge have different capability, attitude and interest during recording the $\mathrm{ICH}$, but all of them are indispensable and interrelated forces.In the rural area, the elderly ordinary people think that they are far from the specialty work of ICH safeguarding and recording. In fact, they are the most loyal inheritors and guardians of traditional skills and folk customs, and also the main source for creating the authentic and integral records. The participation of the whole public can make the ICH records "taken from the folk and used for folk"

\subsubsection{Strengthening professional guidance to ensure the quality of public participation}

ICH listed in safeguarding inventories of all levels are often recorded by the related government departments and recoeds are kept centrally. While for a lot of ICH items that have not been listed in inventories, records are scattered, even not be recorded, local individuals are the main power of recording them. These recording activities are casual, not professional. To improve the records quality, the government departments should provide enough professional guidance on what to record, how to record,etc.

First of all, recording scope should be defined. The recording scope should cover the emergence, development, evolution, protection, inheritance and all activities of the cultural item. So the recording activity should go on constantly. Modern technologies and equipment should be used as much as possible. It is not only beneficial to the preservation and dissemination in the network environment, but also make the factors that can not be reflected by pictures and texts (such as feeling, strength and skills, etc.) can be collected and feedback.

Secondly, records appraisal must be emphasized enough. ICH ( such as customs, etiquette, folk music and dance) come from local people's everyday life. Therefore, the value of ICH records must be judged by the local people. On the basis of their daily life, the public understand its value in continuing the national spirits, propagating the national concepts, and maintaining the national emotions. From the perspective of records management, the public needs to know the records appraisal work, including its significance, content and methods. The public should learn to judge the records' value, authenticity and retention period from the factor of content, source, practice and external characteristics. Comparison, content analysis, verification and other different methods should be used in records appraisal.

Thirdly, ICH records need to be systematically managed through specialty methods such as classification, arrangement, serial coding and so on. The public needs to know the classification of ICH items and the classification of records belong to the same ICH item. 
These skills and knowledge can help to turn the scattered and disorderly records into systematic records resources.

Finally, records preservation is also an urgent problem to be solved. In our investigation, we found that due to the unsatisfied storage conditions, a large number of records kept in the folk faced problems such as paper yellowing and crisping, bitten by insects and mice, unclear old photos and images, and unable to be played discs. Therefore, the public needs to know the basic preservation skills and knowledge, measures. The public should know the appropriate conditions for keeping the records in proper carriers, and the alternative repair plans and channels for seeking help in case of problems

\subsubsection{Optimizing the process of public participation}

Firstly, the composition of the public needs to be analyzed. The public can be divided into different parts, such as universities and research institutions, social groups, local elites, inheritors, ICH enthusiasts and ordinary people, etc. Every part has advantages and disadvanges. For example, universities and research institutions have advantages on theoretical literacy and are good at grasping the basic characters and regular patterns through appearances. Experts and scholars from fields of records management, culture, tourism, literature and art can provide adequate theoretical guidance for recording ICH. Most social groups (such as societies and associations) are devoted to a certain field, with relatively complete and standardized organizational structure and management system. Their members with high cultural literacy can undertake the tasks of organization, communication and coordination in the ICH recording work. Local cultural elites have strong influence and appeal in local areas, and often make outstanding contributions to the inheritance, protection and innovation of local culture. The inheritors are the "living soul" of ICH and grasp the essence of ICH, however, their cultural literacy, cultural consciousness and recording capability are very different from each other. ICH enthusiasts are a very energetic group of the public. Many of them record ICH actively, upload and share ICH information through websites, micro-blog, WeChat and other media. Ordinary people is the largest group of the public. ICH is closely related with their daily life. Every member of the public is an important component in the recording of ICH. They must complement and combine with each other.

Secondly, the process of public participation needs to be optimized according to the "Folk-Government" model. ICH is rooted in the local daily life. Recording ICH needs to adopt "Folk-Government" model, that is to say, the public is the main power under the help and support of the government, so that the ICH recording is carried out in the natural space. The public participation process should be optimized as follows: When an ICH item proposed to be recorded (proposed by the government or the public), this proposal will be submitted to the local records management department. After accepting the proposal, the records management departments decompose the recording work into several tasks (include but not limited to records collection, arrangement, preservation, utilization, digitalization etc.) ,interpret every task in detail, provide proper support, including methods, standards, content, and all that need be paid attention to. And then records department should release the tasks and recruit volunteers through television program, website and other new media. After releasing, the public may apply for certain tasks according to their abilities, interests and hobbies. When the number of enrolled volunteers reaches a certain threshold, the volunteer team is established. The volunteer team will be divided into different groups based on the tasks for recording ICH. For instance, there are groups for collection, for organization, for preservation, for utilization, for propaganda, for digitalization, etc. The records departments will arrange records managers for each group to guide, supervise and assist in the completion of their tasks. 
To ensure the recording quality, the recording process should be embedded with threelayer reviews. The first layer review is undertaken by the members of the same task group to find and reserve quality problems such as not implement standards and any other problems during recording. After completing their own tasks, volunteers may submit the results on the platform, so as to facilitate other members to review and find out quality problems. So the second layer review is taken by members of other teams, to find not authenticity, not accurate, non-standard or any other problems. To encourage volunteers to actively participate in the review, proper rewards and honorary titles are needed. The third layer review is undertaken by the experts group, which composed of experts from records management, archival science and other related fields according to the category and characteristic of ICH. The experts group's is responsible for review if the recording process is undertaken scientifically and if the ICH can be safeguarded by those records. In the whole recording process, the decomposition, distribution, implementation, guidance and review are carried out according to the characteristics, existing situation and requirement of the ICH.

A drop of water can reflect the brilliance of the sun, ICH can reflect the style and appearance of local life. The breadth and depth of ICH recording need to be expanded. Scientific and effective public participation is the main source of ICH recording. However, public participation is still in its primary stage. The public participation needs to be optimized through the professional guidance, through redesigning the public participation model and process, through strengthening the government proper support, and through analyzing and developing different member's advantages and disadvantages so as to cooperate together.

\section{References}

1. T. Janke and L. Iacovino, Arch. Sci. 12, 6 (2012)

2. T. Cook, Arch. Sci. 6, 13 (2013)

3. S. Pietrobruno, Int. J. Herit. Stud. (2014)

4. C. Guccio, M. F. Martorana, I. Mazza, and I. Rizzo, in Cult. Herit. a Chang. World (2016)

5. G. Cozzani, F. Pozzi, F. M. Dagnino, A. V. Katos, and E. F. Katsouli, Pers. Ubiquitous Comput. (2017) 